\title{
Monitoring Dehydration and Clearing in Tissue Processing for High-Quality Clinical Pathology
}

\author{
Melissa L. Lerch,, Daniel R. Bauer, ${ }^{2}$ Abbey Theiss, ${ }^{2}$ David Chafin, ${ }^{2}$ Michael Otter, ${ }^{2}$ and Geoffrey S. Baird ${ }^{1}$
}

The development of precision testing for disease diagnosis has advanced medicine by specifically matching patients with drugs to treat specific diseases. High-quality diagnostics start with high-quality tissue specimens. The development and optimization of tissue handling and processing have lagged behind bioassay development. Ultrasound time-of-flight (TOF) technology has been successfully used to monitor the critical processing step of tissue fixation with formalin. In this study, we expand the use of this technology to monitor tissue dehydration and clearing by analyzing TOF signals from 270 different specimens, representing 13 different tissue types obtained through surgical resections. We determined the time constant $\tau_{90}$ for each tissue type for the following tissue processing solvents: $70 \%$ ethanol, $90 \%$ ethanol, $100 \%$ ethanol, and xylene. The TOF signals were correlated with tissue morphology to ensure that high-quality tissue was produced. Tissues can be grouped into those exhibiting fast and slow reagent diffusion. We monitored incomplete dehydration of tissue by skipping a key processing step, dehydration in absolute ethanol, and then correlated the $\tau_{90}$ with poor histomorphology, demonstrating that the technique can detect significant processing errors. Ultrasound TOF technology can therefore be used to monitor all phases of tissue processing cycle and yields an important preanalytical quality metric.

Keywords: tissue processing, preanalytics, dehydration, clearing, quality assurance, immunohistochemistry

\section{Introduction}

$\mathrm{C}$ OMPANION DIAGNOSTICS ARE being developed alongside therapeutics to provide the right patients with the right therapies at the right time, the central goal of precision medicine. The journey toward this goal is fraught with challenges, not the least of which is summed up in the old computer science saying, "Garbage In, Garbage Out," which in this case indicates that effective and accurate diagnostic tests require high-quality input tissue specimens. Alas, advances in diagnostic test development have far outpaced advances in tissue preservation science, including fixation and processing steps, on which those diagnostic tests depend. ${ }^{1}$ Despite an overall push toward so-called "personalization" of medical care, especially in the diagnosis and treatment of cancer, tissue fixation and processing have seemingly solidified into a onesize-fits-all approach even as studies have indicated that each tissue specimen could be optimized for each diagnostic assay. ${ }^{2}$

That diagnostic results are compromised when tissue is not adequately fixed and/or processed is not a controversial statement. It is well known, for example, that immunohis- tochemistry results are confounded when tissue is not properly processed, but fewer studies have focused on this aspect of preanalytical tissue variability. ${ }^{3,4}$ The mechanisms underlying these preanalytical errors are not always well understood, although in some cases, hypotheses have been supported, such as the finding that incomplete dehydration leaves residual water within the tissue leading to hydrolysis of protein biomarkers and nucleic acids. ${ }^{5}$ Although few other studies have specifically examined the effects of incomplete dehydration and clearing, it is a well-known problem in the clinical pathology laboratory.

The current approach to solving the problem of preanalytical tissue processing errors, which is simply ensuring that all tissue processing steps last long enough so that even the most challenging tissue specimens have time to reach equilibrium with reagents, is unsatisfying for three reasons. First, this approach represents capitulation in the face of a potentially solvable biochemical problem. Second, fixing and processing for arbitrarily long periods maximize the overall time of analysis, increasing diagnostic turnaround time and introducing delays in histopathology workflows

\footnotetext{
${ }^{1}$ Department of Laboratory Medicine, University of Washington Medical Center, Seattle, Washington.

${ }^{2}$ Ventana Medical Systems, Inc., Tucson, Arizona.

(C) Melissa L. Lerch, et al., 2019; Published by Mary Ann Liebert, Inc. This Open Access article is distributed under the terms of the Creative Commons Attribution Noncommercial License (http://creativecommons.org/licenses/by-nc/4.0/) which permits any noncommercial use, distribution, and reproduction in any medium, provided the original author(s) and the source are cited.
} 
that can disrupt or extend the work of dedicated histotechnology staff members. Third, and perhaps most important, neglecting to study and monitor tissue processing steps prevents the diagnostic laboratory from collecting important metrics of quality that could be used to enhance the value of many diagnostic tests.

We believe that time-of-flight (TOF) ultrasound measurements are an attractive candidate to serve as the technology that solves this problem. In TOF ultrasound, highfrequency $(4 \mathrm{MHz})$ acoustic pulses traverse the tissue and are compared to pulses through the reagent, the differential between these waveforms are calculated as $\Delta \mathrm{TOF}$. As the reagent diffuses into the tissue, it reaches equilibrium. We have already demonstrated that TOF ultrasound can be used to monitor neutral-buffered formalin (NBF) diffusion into tissue and can be used to prevent overfixation or underfixation of tissue, ${ }^{6}$ and in this study, we have used this technology to monitor additional tissue processing steps, including dehydration and clearing with organic solvents.

In this study, we monitored tissue processing with TOF ultrasound technology from 270 tissue samples, comprising a range of different tissue types to measure the dehydration steps that are usually employed in tissue processing before histopathology. We have monitored TOF using a routine tissue processing protocol (TPP) when dehydrating tissue in a series of reagent ethanol solutions (ranging from $70 \%$ to $100 \%$ ethanol in water), and thereafter tissue clearing in xylene. We compared the morphology of the tissue specimens with the TOF profiles to ensure that high-quality tissue had been generated. To demonstrate sensitivity of the technique to errors in processing, we intentionally skipped a critical processing step and were able to observe that we could detect disrupted TOF traces, and measured diffusion times that would have predicted poor tissue morphology.

\section{Methods and Materials}

\section{Tissue collection and handling}

Tissue samples were collected at the University of Washington Medical Center (UWMC) under an exemption of written consent granted by the University of Washington's Institutional Review Board and were supplied as deidentified material by the UWMC Northwest Biotrust. All tissue samples were collected fresh from surgical excisions. All specimens were either sampled as a tissue core with a $6 \mathrm{~mm}$ punch biopsy tool or cut with a blade to be roughly $6 \times 6 \mathrm{~mm}$ cubes. In practice, due to the variably compressible nature of many human tissues, samples ranging from 4 to $7 \mathrm{~mm}$ thickness were included in the study, although the majority of samples $(85 \%)$ were $\sim 6 \mathrm{~mm}$ thick.

\section{TOF measurement and retrofit tissue processor}

To process histological tissue samples, while concomitantly measuring ultrasound TOF across the sample, a commercial "Dip and Dunk" -style tissue processor (Lynx II; Electron Microscopy Sciences) was retrofit with acoustic monitoring technology as previously described. ${ }^{7,8}$ Briefly, a custom-developed digital acoustic interferometry algorithm was used to detect the small acoustic phase retardation resulting from fluid exchange within the tissue with subnanosecond precision. Tissue was held in subdivided mesh biopsy cassettes (CellSafe 5 Biopsy Cassette; CellPath
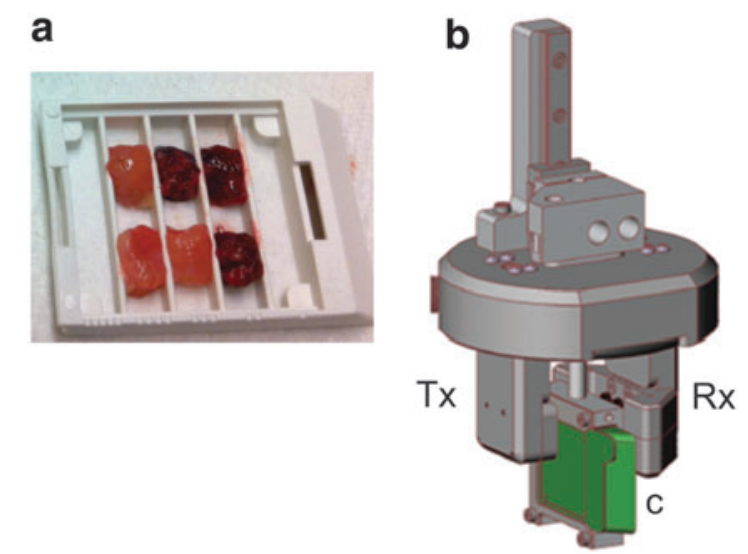

FIG. 1. TOF ultrasound device and cassette. (a) CellPath subdivided biopsy cassette loaded with tissue $(6 \mathrm{~mm}$ punches of colon and lung tissue). (b) Schematic of TOF ultrasound scan head illustrating the position of the cassette when tissue is processed and monitored. Tx, transmitting transducers; Rx. receiving transducers; and c, cassette. TOF, time-of-flight.

USA) (Fig. 1a) to measure multiple samples at one time. Figure $1 \mathrm{~b}$ shows a schematic of the scan head illustrating the position of the tissue cassette between the transmitting and receiving transducers. The cassette holder was mechanically translated so that diffusion throughout the tissue sample could be monitored with a spatial resolution of $1 \mathrm{~mm}$.

\section{TOF signal transformation and analysis}

Passive diffusion of reagents into tissue gradually changes the sound velocity of the tissue. Consistent with expectations from Fick's Law, the sample initially experiences rapid exchange from the large concentration gradient and gradually trends toward no net fluid exchange as diffusive equilibrium is achieved. Individual TOF signals were filtered with a low-order median filter and a third-order Butterworth filter to reduce noise. To get a representative metric of the rate of fluid exchange, all individual TOF signals were averaged together to produce a single TOF curve representing the average rate of diffusion of the entire specimen. This approach also mitigated the effects of substantial spatial heterogeneity within the tissue. Finally, the TOF change during ethanol and xylene diffusion was well correlated with a single exponential decay, so average diffusion curves were fit to a single exponential function using nonlinear regression. Although the acoustic properties of tissue could change for a variety of reasons during tissue processing, that is, tissue shrinking, distortion, or changing compressibility, we have previously shown that the TOF signal is predominately, if not completely, due to diffusion of fluids into and out of the tissue. ${ }^{7}$

\section{TOF tissue processing protocols}

Diffusion of tissue processing reagents into tissue using a standard TPP was monitored using TOF in the following reagents: $70 \%$ ethanol in water, $90 \%$ ethanol in water, $100 \%$ ethanol, and $100 \%$ xylene. The TOF technology was not used to monitor paraffin infiltration into cleared tissue because the current design of the prototype monitoring device 
makes it challenging to remove hardened wax from the ultrasound transducers after measurement.

Complete TPP. Tissues were fixed in NBF using a twotemperature fixation method in which the tissue is initially placed in $4^{\circ} \mathrm{C}$ NBF for 10 hours followed by 2 hours in $45^{\circ} \mathrm{C}$ NBF. No TOF signal is reported in NBF in this study because those results have been previously published. ${ }^{6}$ In this protocol, we used long incubation times of 8 hours in each reagent to allow ample time for complete diffusion of the reagents and for the TOF signal to achieve stable equilibrium. Times and temperatures for all reagents in the custom TOF protocol are displayed in Table 1.

Rapid TPP. For this protocol, the time in each reagent was reduced to reflect a typical overnight tissue processing run. Fixation was accomplished with 2 hours of incubation in $4^{\circ} \mathrm{C} \mathrm{NBF}$ and then 2 hours in $45^{\circ} \mathrm{C} \mathrm{NBF}$ as previously described. ${ }^{9}$ Dehydration and clearing steps were as follows: 4 hours in 70\% ethanol, 3 hours in 90\% ethanol, 3 hours in $100 \%$ ethanol, and 3 hours in xylene.

Histology preparation. For morphology comparisons, tissue was incubated in paraffin wax offline (Low Melt Wax; EMS) for 1 hour at $60^{\circ} \mathrm{C}$ following the instrument's terminal xylene incubation. Tissue samples were thereafter embedded in paraffin and $4 \mu \mathrm{m}$ sections were cut from paraffin blocks and baked onto glass slides for immunohistochemistry.

Incomplete dehydration and morphology comparison. In this protocol, we demonstrate the ability to detect an error in tissue processing by the TOF and intentionally misprocess the tissue in a way that leads to morphologic artifacts. We omitted the $100 \%$ ethanol incubation in the processing protocol, and instead directly moved tissue from $90 \%$ ethanol into xylene so that residual water would be left in the tissue. This created dehydration artifacts in the tissue that was studied both by examining TOF traces and the resulting histopathologic appearance of tissue morphologies of normally processed and misprocessed tissue. Both specimens were fixed for at least 24 hours at room temperature in NBF.

Data reporting. In reporting diffusion of NBF into tissue, the decay constant ( $\tau$ : time to $63 \%$ change in TOF diffusion amplitude, in hours) was correlated to tissue histomorphology. ${ }^{6}$ In this study, this same constant will be referred to as $\tau_{63}$ (hours), and the time to $90 \%$ signal change will be indicated as $\tau_{90}$ (hours).
Immunohistochemistry. Immunohistochemistry was performed on an automated VENTANA Discovery XT staining instrument according to the manufacturer's recommendations. Slides were deparaffinized using EZPrep (Ventana Medical Systems, Inc.) at $90^{\circ} \mathrm{C}$. Epitope retrieval, antibodies, and treatment conditions were selected according to package inserts. Slides were developed using the OptiView DAB IHC Detection kit (Ventana Medical Systems, Inc.) and counterstained with hematoxylin. Whole slide images were obtained using an Aperio slide scanner.

\section{Results}

\section{Monitoring dehydration and clearing using TOF ultrasound technology}

We have previously demonstrated that TOF ultrasound technology can be used to monitor formalin fixation in real time in a variety of tissues. ${ }^{6}$ In this study, we evaluated the ability of the same TOF ultrasound system to monitor many stages of tissue processing, from dehydration with increasing concentrations of ethanol to clearing in $100 \%$ xylene. The sound velocities of tissue processing reagents decrease from $1460 \mathrm{~m} / \mathrm{s}$ in NBF to $1245 \mathrm{~m} / \mathrm{s}$ in $70 \%$ ethanol, $1178 \mathrm{~m} / \mathrm{s}$ in $90 \%$ ethanol, and $1144 \mathrm{~m} / \mathrm{s} 100 \%$ ethanol, ${ }^{10}$ and the velocity then increases to $1330 \mathrm{~m} / \mathrm{s}$ in xylene (Table 1) ${ }^{11}$ The TOF ultrasound system monitors these changes as the reagents diffuse into tissue specimens.

Tissue was selected for this study to represent the broad range of diffusion rates observed in human tissues. ${ }^{6}$ Tissue was selected from those with the fastest fluid diffusion rates (lung, kidney, and breast), moderate diffusion rates (tonsil), and slow diffusion rates (adipose and liver). If available, cancers from these tissues, primarily carcinomas, were also collected, but cancer was not the focus of this study and thus comprehensive data on cancer tissue processing were not collected. The results from all tissue types are compiled in Supplementary Figure S1 and Supplementary Table S1.

\section{Complete TPP}

To ensure that the complete diffusion of each reagent into the tissue and stabilization of the $\triangle \mathrm{TOF}$ signal were achieved, long incubation periods of 8 hours were used in the Complete TPP (Table 1). We collected 270 tissues from

Table 1. Protocols and Sample Numbers

\begin{tabular}{|c|c|c|c|c|c|c|c|c|}
\hline \multirow[b]{2}{*}{ Reagent } & \multicolumn{3}{|c|}{$\begin{array}{c}\text { Complete tissue } \\
\text { processing protocol }\end{array}$} & \multicolumn{3}{|c|}{$\begin{array}{c}\text { Rapid tissue } \\
\text { processing protocol }\end{array}$} & \multicolumn{2}{|c|}{$\begin{array}{c}\text { Sound velocity } \\
\text { of reagent }\end{array}$} \\
\hline & $\begin{array}{l}\text { Temperature } \\
\left({ }^{\circ} \mathrm{C}\right)\end{array}$ & $\begin{array}{l}\text { Time } \\
(h)\end{array}$ & $\begin{array}{c}\text { No. of } \\
\text { tissue samples }\end{array}$ & $\begin{array}{l}\text { Temperature } \\
\left({ }^{\circ} \mathrm{C}\right)\end{array}$ & $\begin{array}{l}\text { Time } \\
(h)\end{array}$ & $\begin{array}{c}\text { No. of } \\
\text { tissue samples }\end{array}$ & $C_{s}$ & $\Delta C_{s}$ \\
\hline $10 \% \mathrm{NBF}$ & 6 & 10 & na & 6 & 2 & na & 1460 & \\
\hline $10 \% \mathrm{NBF}$ & 45 & 2 & na & 45 & 2 & na & 1460 & \\
\hline 70\% Ethanol & 20 & 8 & 185 & 20 & 4 & 63 & 1245 & -215 \\
\hline 90\% Ethanol & 20 & 8 & 200 & 20 & 3 & 63 & 1178 & -67 \\
\hline $100 \%$ Ethanol & 20 & 8 & 173 & 20 & 3 & 55 & 1144 & -34 \\
\hline Xylene & 20 & 8 & 99 & 20 & 3 & 61 & 1330 & 186 \\
\hline Paraffin & & & & & & & 1241 & -89 \\
\hline
\end{tabular}

TOF fixation and tissue processing steps for TOF protocols used to study dehydration and clearing through the following reagents: $70 \%$ ethanol, $90 \%$ ethanol, $100 \%$ ethanol, and absolute xylene. $\mathrm{C}_{\mathrm{s}}$ is the speed of sound $(\mathrm{m} / \mathrm{s})$ and $\Delta \mathrm{C}_{\mathrm{s}}$ is the change in the speed of sound between two reagents $(\mathrm{m} / \mathrm{s})$.

na, not applicable; NBF, neutral-buffered formalin; TOF, time-of-flight. 
Table 2. Diffusion Time of Alcohols and Xylene into Tissue

\begin{tabular}{|c|c|c|c|c|c|c|c|c|c|c|}
\hline \multirow[b]{2}{*}{ Tissue } & \multirow{2}{*}{$\frac{\begin{array}{c}\tau_{63} \\
(\text { hours })\end{array}}{N B F^{\mathrm{a}}}$} & \multicolumn{4}{|c|}{$\begin{array}{c}\tau_{63} \\
\text { (hours) }\end{array}$} & \multirow[b]{2}{*}{$\begin{array}{l}\text { No. of } \\
\text { tissues }\end{array}$} & \multicolumn{4}{|c|}{$\begin{array}{c}\tau_{90} \\
\text { (hours) }\end{array}$} \\
\hline & & $\begin{array}{c}70 \% \\
E t O H\end{array}$ & $\begin{array}{l}90 \% \\
E t O H\end{array}$ & $\begin{array}{l}100 \% \\
\mathrm{EtOH}\end{array}$ & Xylene & & $\begin{array}{c}70 \% \\
E t O H\end{array}$ & $\begin{array}{l}90 \% \\
\text { EtOH }\end{array}$ & $\begin{array}{l}100 \% \\
\mathrm{EtOH}\end{array}$ & Xylene \\
\hline \multicolumn{11}{|c|}{ Complete tissue processing protocol } \\
\hline Kidney & 1.13 & 1.29 & 0.61 & 0.47 & 0.46 & 44 & 2.97 & 1.40 & 1.08 & 1.06 \\
\hline Breast & 1.38 & 1.67 & 0.98 & 1.18 & 0.52 & 45 & 3.85 & 2.26 & 2.72 & 1.20 \\
\hline Liver & 3.23 & 1.66 & 0.7 & 0.62 & 0.58 & 11 & 3.82 & 1.61 & 1.43 & 1.34 \\
\hline Adipose & 3.69 & 3.15 & 1.78 & 2.55 & 0.93 & 7 & 7.25 & 4.10 & 5.87 & 2.14 \\
\hline Skin & 2.6 & 1.69 & 1.67 & 2.03 & na & 5 & 3.89 & 3.85 & 4.67 & na \\
\hline Tonsil & 2.75 & 1.32 & 0.54 & 0.48 & 0.7 & 16 & 3.04 & 1.24 & 1.11 & 1.61 \\
\hline Lung & 1.06 & 1.24 & 0.51 & 0.42 & na & 3 & 2.86 & 1.17 & 0.97 & na \\
\hline Colon & 1.37 & 1.3 & 0.62 & 0.76 & 0.59 & 22 & 2.99 & 1.43 & 1.75 & 1.36 \\
\hline \multicolumn{11}{|c|}{ Rapid tissue processing protocol } \\
\hline Kidney & 1.13 & 1.61 & 0.69 & 0.61 & 0.55 & 15 & 3.71 & 1.59 & 1.40 & 1.27 \\
\hline Breast & 1.38 & 2.15 & 1.16 & 1.24 & 0.56 & 34 & 4.95 & 2.67 & 2.86 & 1.29 \\
\hline
\end{tabular}

Time constants $\tau_{63}$ and $\tau_{90}$ for alcohols and xylene by tissue type for complete TPP and rapid TPP.

${ }^{a}$ Previously published data. ${ }^{6}$

TPP, tissue processing protocol.

13 different tissue types (Table 2) and monitored the diffusion time using TOF. The time constant $\tau_{90}$ for $70 \%$ ethanol ranged from 2.86 to 7.25 hours, for $90 \%$ ethanol ranged from 1.17 to 4.10 hours, for $100 \%$ ethanol ranged from 0.97 to 5.87 hours, and for xylene ranged from 1.06 to 2.14 hours. The range of values of $\tau_{90}$ varies both by tissue type and reagent type (Fig. 2a).

The time needed for reagent diffusion in the dehydration and clearing steps of tissue processing is shown as an average for all tissue types (Fig. 2b), but it varied in magnitude for each tissue type: kidney (Fig. 2c), liver (Fig. 2d), colon (Fig. 2e), breast (Fig. 2f), and adipose (Fig. 2g). The functional form of the TOF signal resulting from fluid exchange with the processing reagents was best fit with a single exponential $\left(R^{2}\right.$ adj $=0.99 \pm 0.02$; deviation from fit $=1.5 \% \pm 1$ of signal amplitude). The TOF trace associated with diffusion of xylene switches direction ("flips") in adipose tissue versus in all other observed tissues. We found that the TOF traces for the diffusion of xylene into breast tissue followed two patterns, corresponding to either the flipped xylene diffusion trace seen in adipose tissue (Fig. 2h) or an unflipped xylene diffusion trace (Fig. 2i). These two patterns are likely observed because breast tissue can be composed predominantly of either adipose or fibroglandular components.

\section{Rapid TPP}

Once the time for dehydration and clearing was established, a new protocol was designed to optimize the time for the tissue processing that would be relevant to a clinical pathology laboratory using a routine TPP. We combined this processing run with the rapid cold-hot fixation protocol to create high-quality fixed tissue within 18 hours of collection (Table 1). ${ }^{9}$ The morphology of the tissue was examined by standard hematoxylin and eosin (H\&E) analysis and compared to the TOF curves.

Tissue was collected from 15 kidney tissues and 34 breast tissues for the Rapid TPP and morphology analysis (Table 2). For the breast tissue, the average TOF trace (Fig. 3a) and the time constant $\tau_{90}$ for $70 \%$ ethanol was 4.95 hours, 2.67 hours for $90 \%$ ethanol, 2.86 hours for $100 \%$ ethanol, and clearing in xylene was 1.29 hours. For the kidney tissue, the average TOF trace (Figure $3 b$ ) and the $\tau_{90}$ for $70 \%$ ethanol was 3.71 hours, $90 \%$ ethanol was 1.59 hours, $100 \%$ ethanol was 1.40 , and clearing in xylene was 1.27 hours. The largest variation between the Rapid TPP and the Complete TPP was in the $70 \%$ ethanol. As expected, there is a slight increase in the $\tau_{90}$ as the alcohol gradient increases because the incubation time has decreased significantly from 8 hours in each reagent to 4 hours in $70 \%$ ethanol and 3 hours in all other reagents.

Morphology of these kidney and breast tissues was examined by standard H\&E (Fig. 3). Representative images from different breast tissue (Fig. 3a) and kidney tissue (Fig. 3b) show preservation of tissue features expected for each tissue type. The breast tissue has clear ducts and the kidney tissue has distinct glomeruli.

\section{Incomplete dehydration protocol}

Finally, the system was perturbed to compare tissue from the same patient in two conditions. One tissue sample was improperly dehydrated by skipping the final incubation in $100 \%$ ethanol, which typically removes the remaining water from the tissue preparing it for the clearing step, and a

FIG. 2. TOF data for dehydration and clearing of various tissues. (a) Summary of $\tau_{90}$ for all reagents. (b) Summary of all tissues except adipose and breast TOF trace. (c) Kidney tissue average TOF trace through all reagents with SD using the complete TPP (40 hours). (d) Liver tissue TOF trace. (e) Colon tissue average TOF trace with SD. (f) Breast tissue average TOF trace with SD. (g) Adipose tissue average TOF trace with SD. (h) TOF trace for likely fibrous breast tissue. (i) TOF trace for likely fatty breast tissue. SD, standard deviation; TPP, tissue processing protocol. 

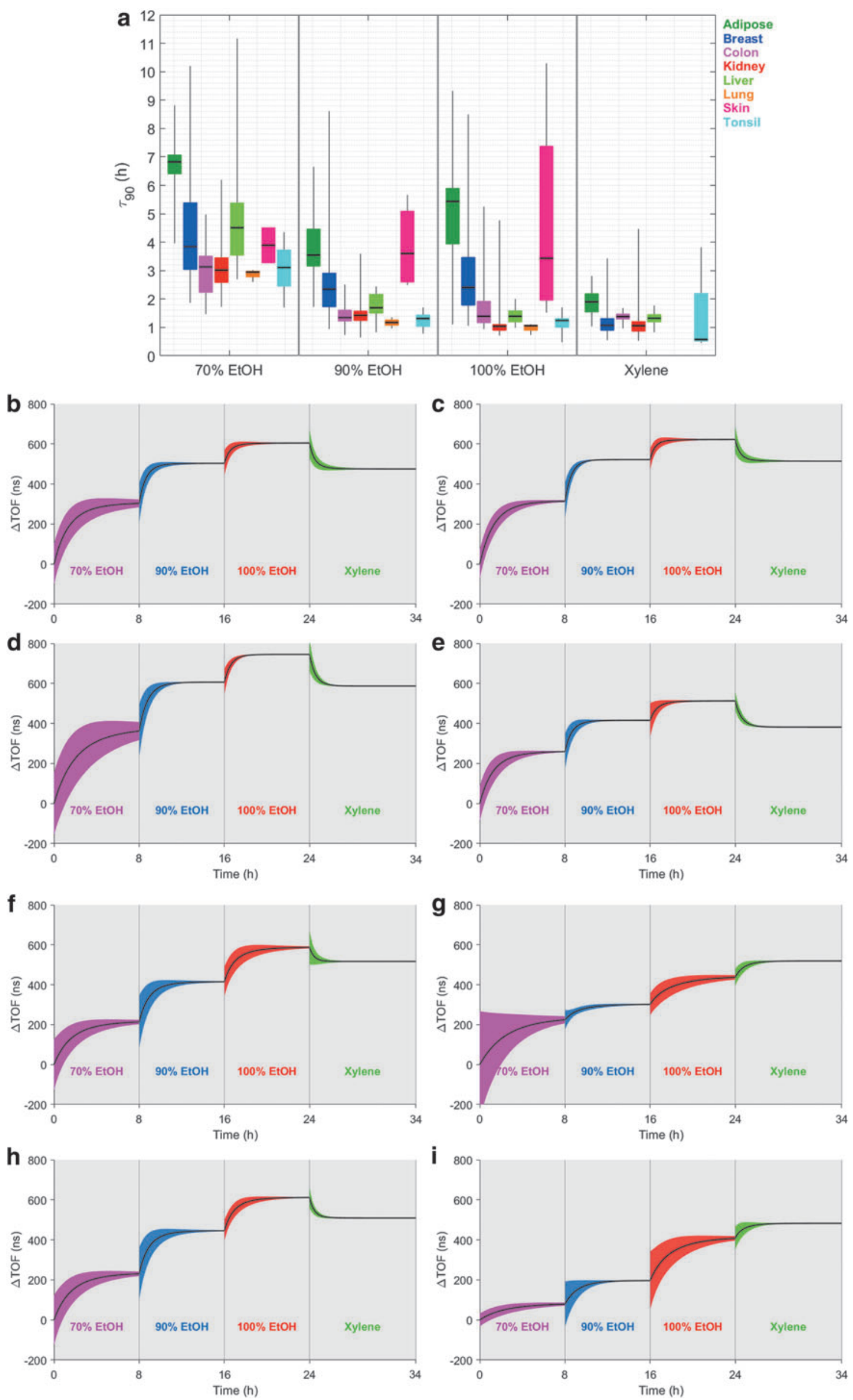

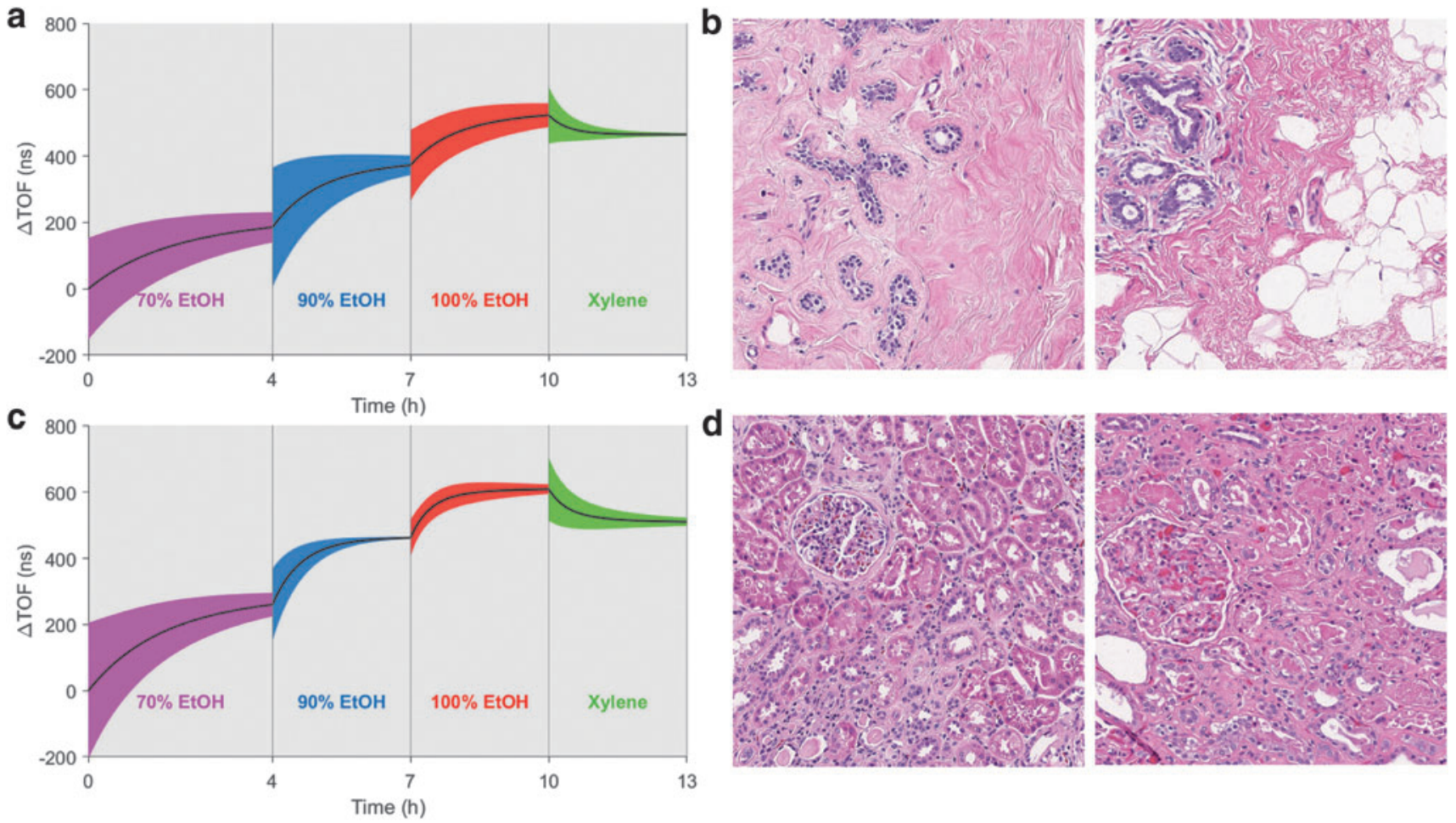

FIG. 3. Rapid tissue processing protocol for dehydration and clearing for breast and kidney TOF data. (a) Average TOF trace for breast tissue (b) representative morphology for breast. (c) Average TOF trace for kidney (d) representative morphology of tissue for kidney using $\mathrm{H} \& \mathrm{E}$ at $20 \times$ magnification with $100 \mu \mathrm{m}$ scale bars. H\&E, hematoxylin and eosin.

paired tissue sample was properly processed by inclusion of the $100 \%$ ethanol step based on the Rapid TPP (Table 3). The tissue for this experiment was fixed for 24-35 hours in $\mathrm{NBF}$ at room temperature without TOF monitoring. Morphology of the tissue was compared using a standard H\&E stain.

The TOF traces for the properly processed tissue for each dehydration and clearing step follow the same patterns observed in previous experiments for kidney (Fig. 4a). The time constant $\tau_{90}$ for the $90 \%$ ethanol dehydration was $0.78 \pm 0.04$ hours with an adjusted $R^{2}$ of 0.997 and the time constant $\tau_{90}$ for xylene was $0.57 \pm 0.07$ hours with an adjusted $R^{2}$ of 0.995 . The TOF traces for dehydration of the improperly processed tissue (Fig. 4c) have the same patterns as properly processed tissue for the $90 \%$ ethanol dehydration step, with time constant $\tau_{90}$ of $0.82 \pm 0.21$ hours and an adjusted $R^{2}$ of 0.999 to fit the actual TOF trace to a single

TABle 3. InCOMPlete DehydRATION EXPERIMENTS

\begin{tabular}{lccccc}
\hline & \multicolumn{2}{c}{$\begin{array}{c}\text { Proper } \\
\text { dehydration }\end{array}$} & & \multicolumn{2}{c}{$\begin{array}{c}\text { Incomplete } \\
\text { dehydration }\end{array}$} \\
\cline { 2 - 3 } \cline { 5 - 6 } Reagent & $\begin{array}{c}\text { Temperature } \\
\left({ }^{\circ} \mathrm{C}\right)\end{array}$ & $\begin{array}{c}\text { Time } \\
(h)\end{array}$ & & $\begin{array}{c}\text { Temperature } \\
\left({ }^{\circ} \mathrm{C}\right)\end{array}$ & $\begin{array}{c}\text { Time } \\
(h)\end{array}$ \\
\hline $10 \% \mathrm{NBF}^{\mathrm{a}}$ & 20 & 24 & & 20 & 34 \\
$70 \%$ Ethanol & 20 & 4 & & 20 & 4 \\
$90 \%$ Ethanol & 20 & 3 & & 20 & 3 \\
$100 \%$ Ethanol & 20 & 3 & & 20 & 0 \\
Xylene & 20 & 3 & & 20 & 3 \\
wax $^{\mathrm{a}}$ & 60 & 1 & 60 & 1 \\
\hline
\end{tabular}

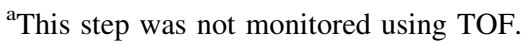

exponential decay, but the $\tau_{90}$ for xylene is considerably longer, at $1.90 \pm 0.5$ hours with an $R^{2}$ of 0.998 to fit the actual TOF trace to a single exponential decay. This change in xylene diffusion corresponded to a decrement in tissue histomorphology (Fig. 4b vs. 4d) and to physical properties of the misprocessed tissue (brittleness, tendency to fold and tear, overall assessments by the histotechnology staff that the tissue was unsuitable for sectioning) (Fig. 4).

The TOF traces for the properly processed breast tissue were consistent with previous experiments performed on fatty breast tissue (Fig. 4e). The time constant $\tau_{90}$ for the $70 \%$ ethanol incubation was 2.92 and $R^{2}$ of 0.998 for the $70 \%$ ethanol step and $1.48 \pm 0.16$ hours and $R^{2}$ of 0.999 for the $90 \%$ ethanol dehydration step $\left(R^{2}\right.$ values in these experiments correspond to a fit of the actual TOF trace to a single exponential decay). The $\tau_{90}$ for the xylene incubation was $0.58 \pm 0.10$ hours for xylene and $R^{2}$ of 0.982 . The TOF traces for the improperly processed breast tissue (Fig. 4g) appeared most similar to traces observed in fibrous breast tissue during the dehydration steps, with the $\tau_{90}$ for the $70 \%$ ethanol of $0.91 \pm 0$ hours and $R^{2}$ of 0.997 , and $90 \%$ ethanol dehydration of 0.56 and $R^{2}$ of 0.998 . Solvent diffusion proceeded more slowly in the xylene step for improperly processed breast tissue than in properly processed tissue, and the direction of the TOF change flipped, with a decay constant of $0.79 \pm 0.25$ hours and $R^{2}$ of 0.994 . The $\tau_{90}$ observed in the dehydration steps and the directionality of the TOF curve in xylene likely differed between these two properly and improperly processed breast tissue samples as a consequence of differences in the composition (fibrous vs. fatty) of the specific tissue samples used in these experiments (Fig. 4f, g). 

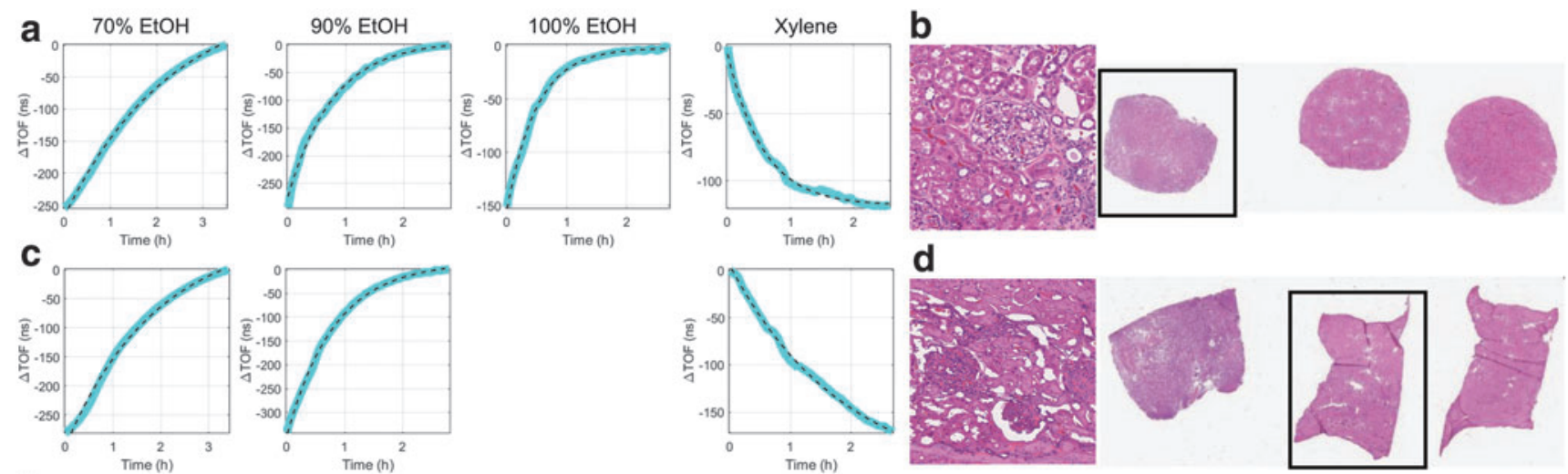

e
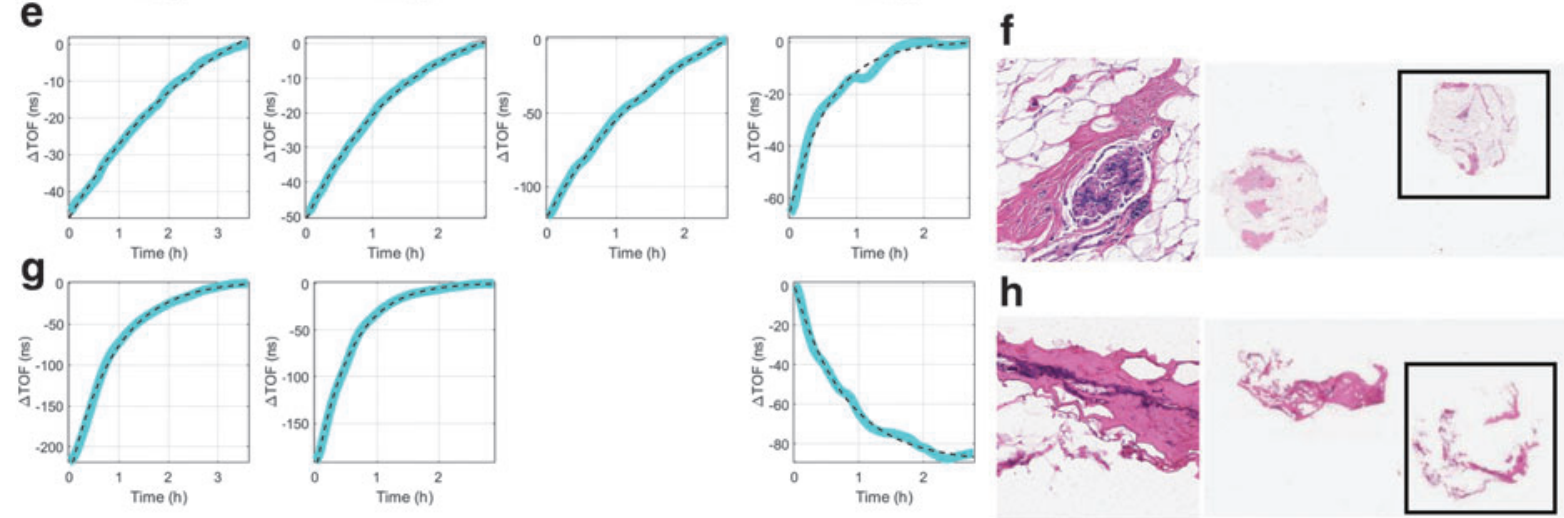

FIG. 4. Morphology of improper dehydration with matched TOF trace. (a) Properly processed normal kidney TOF trace through each reagent for a specific piece of tissue. (b) Properly processed normal kidney morphology of tissue by H\&E at 20x magnification and low-resolution whole slide scan of the three tissue punches. (c) Improperly dehydrated normal kidney TOF trace without $100 \%$ incubation. (d) Improperly processed normal kidney. (e) Properly processed normal breast TOF trace. (f) Properly processed normal breast morphology and whole slide image. (g) Improperly dehydrated normal breast TOF trace without $100 \%$ ethanol incubation. (h) Improperly dehydrated normal breast morphology $20 \times$ magnification with whole slide image. The whole slide images have a box to indicate which tissue was analyzed and displayed for the TOF traces and magnified images. The $20 \times$ magnification images have $100 \mu \mathrm{m}$ scale bars, while whole slide images have a $1 \mathrm{~mm}$ scale bar.

As with the kidney misprocessing experiment, the breast tissue misprocessing experiment demonstrated that the TOF technology was able to detect differences in solvent diffusion that correlated with histomorphologic artifacts. The properly processed breast tissue appeared histologically

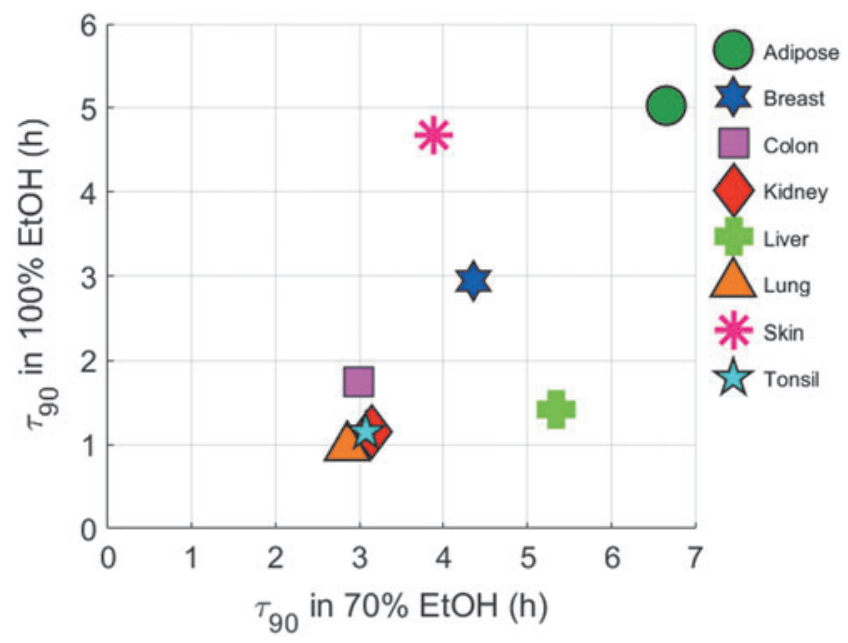

FIG. 5. Effect of diffusion of $70 \%$ ethanol on diffusion of $100 \%$ ethanol by tissue type. normal (Fig. 4f), whereas the improperly processed breast tissue (Fig. 4h) showed artifacts similar to those seen in the improperly processed kidney tissue, such as folded tissue and tears.

\section{Rate of dehydration and clearing in various tissues}

The $\tau_{90}$ of ethanol was compared for $70 \%$ ethanol and $100 \%$ ethanol of different tissues (Fig. 5). Two groups of tissue can be discerned, those that demonstrate rapid reagent diffusion like kidney, colon, and lung, and those that appear to have slower diffusion, such as adipose, skin, and breast. These results are consistent with anecdotal observations made by histotechnologist and with our previous results with diffusion of NBF. Results with diseased (mostly cancerous) tissue were not significantly different than corresponding normal tissue (Supplementary Fig. S1).

\section{Discussion}

In this study, we have demonstrated the ability of the TOF ultrasound technology to monitor the complete tissue processing cycle by monitoring diffusion of processing reagents in 270 tissues from 13 different tissue. We have demonstrated that the system can detect errors in processing that correlate to poor histomorphology, such as incomplete 
dehydration. Therefore, we believe that this TOF ultrasound technology can provide histologic quality metrics and potentially be used for real-time tissue processing monitoring.

Based on the data we collected in real time, we were able to devise a rapid TPP that minimized overall processing time, while ensuring adequate penetration of processing reagents. The resulting protocol yields tissue that is ready for histologic sectioning 18 hours after excision for a variety of tissue types. Tissue types could be broadly split into two groups: those with fast diffusion of ethanol (tonsils, colon, kidney, and lung) and those with slow diffusion of ethanol (adipose, skin, and breast).

We observed greater variability in reagent diffusion with breast tissues, presumably because of the different diffusive properties of fatty and fibroglandular breast tissue. The speed of sound for fibroglandular breast tissue is $1525 \mathrm{~m} / \mathrm{s}$ and typically fatty breast tissue is closer to $1466 \mathrm{~m} / \mathrm{s},{ }^{12}$ with a decrease in velocity associated with increasing age. ${ }^{13}$ This difference in the speed of sound of the tissue, coupled with the speed of sound of the reagent, may explain only part of the difference in the directionality of the TOF trace. Another factor responsible for the change in directionality could be related to the solubility of the lipids of the adipose tissue in xylene, and the fact that the xylene incubation step removes a significant amount of the tissue's mass by extracting the lipid content.

We focused our study on tissue with the same size, $6 \mathrm{~mm}$ punches (or in some cases, scalpel cubes depending on the particular piece of tissue), to determine comparable reagent diffusion times $\tau_{90}$ for specific tissue types. We have used the TOF ultrasound device to measure diffusion in larger tissue (data not shown); however, the absolute values would not be directly comparable between tissues of different sizes. It is possible to use these data to determine complete diffusion of reagents irrespective of tissue size. Heterologous tissue could also be analyzed using this method; however, fatty tissue could confound the diffusion rate $\tau_{90}$ of the last clearing step as discussed for the fatty breast tissue.

We observe some errors during monitoring, resulting from tissue slippage that occurs when tissue shrinks as a result of dehydration or clearing, or during reagent transitions as fluid drains from the cassette. We utilize a specialized cassette that is commercially available, which is subdivided in compartments (Fig. 1a) that fit $6 \mathrm{~mm}$ diameter punches appropriately; however, not all tissue punches maintain their size or shape during routine processing.

Of the 193 tissue samples monitored through all four reagents $(70 \%$ ethanol, $90 \%$ ethanol, $100 \%$ ethanol, and xylene), we were able to collect complete set of measurements on $74 \%$ of the samples, $20 \%$ of samples experienced an error in one of the four reagents, while $6 \%$ of samples experienced an error in two or more of the reagents. The most common source of failure is the tissue sliding within the cassette, although other sources of error can occur (e.g., low ultrasound transmission, poor thermal control, low reagent volume due to underfilling or evaporation, and calibration errors in the TOF calculation). Larger tissues have been analyzed using a larger mesh cassette that fits a single piece of tissue. ${ }^{8}$ Future iterations for this device should consider a custom cassette holder to further reduce tissue movement within the cassette.

It has long been known that incomplete dehydration leads to artifacts and poor morphology in formalin-fixed paraffin- embedded (FFPE) tissue. ${ }^{3}$ In this study, we were able to introduce this error intentionally and monitor its effect on ultrasound TOF, showing that dehydration lengthened xylene diffusion when some water remained within the tissue. Thus, we have demonstrated that our approach can detect problems that correlated with poor downstream tissue quality. The fact that our TOF ultrasound instrument can detect these changes in real time indicates that this approach could detect these differences and allow one to alter conditions and correct errors before they interfere with downstream analyses.

Ultrasound has been reported to speed the fixation process for tissue in formalin. It is likely that the marked temperature increase for the reagent and subsequent increase in the tissue $\left(12^{\circ} \mathrm{C}\right.$ in 40 minutes $)$ may account for the increased speed of fixation. ${ }^{14}$ In the TOF ultrasound technology described herein, the temperature is controlled at $20^{\circ} \mathrm{C}$ throughout the processing protocol. In the absence of temperature control, we observe temperature drift, but not increasing temperature (data not shown). Furthermore, we use a significantly lower power ultrasound beam compared to the $30 \mathrm{~W}(1.1-1.4 \mathrm{MHz})$ administered in the ultrasound fixation studies. We do not anticipate any alterations in the fixation speed as a result of the low-power ultrasound utilized for monitoring.

Ultrasound has been used experimentally for degradation of DNA. Liquids or tissue subjected to sufficient intensity ultrasound can develop acoustic cavitation resulting in DNA breakage from the shearing effects of the microbubble formation. Generally, if DNA degradation is the goal in an experimental setting, low frequency of $20-30 \mathrm{kHz}$ is typical with high power settings. ${ }^{15}$ The high-frequency, lowintensity ultrasound in our monitoring technique is unlikely to generate significant DNA damage.

We did not choose to monitor paraffin wax infiltration in this study, largely because the geometry of our prototype TOF device complicated removal of residual hardened wax from the instrument. This processing step is a crucial part of FFPE tissue production, however, and with modifications to the TOF ultrasound instrument, the technology could be used to monitor wax infiltration as well, since the underlying principle of TOF change would still be present in wax. The speed of sound of liquid paraffin is about $1241 \mathrm{~m} / \mathrm{s}^{16}$ and has a good differential from the speed of sound of xylene $1330 \mathrm{~m} / \mathrm{s},{ }^{11}$ meaning that the detection of the signal as the paraffin infiltrates the tissue should be measurable with our instrument.

There are many potential directions for our next steps with this research. Fixation, dehydration, and clearing times for brain tissue are quite long and could greatly benefit from techniques to optimize the tissue processing steps. While we have measured the fixation times for white and gray matter of brain, we have not yet studied additional tissue processing steps. ${ }^{6}$ The TOF measurements of tissue fixation can be used for predictive processing, which could optimize tissue processing times in real time. Furthermore, the TOF could be used to generate quality scores for every tissue processed in the histotech laboratory, which would ultimately give the pathologist an even greater degree of confidence in their assessment and ultimately the patient diagnosis.

Technological advances in monitoring tissue processing using TOF ultrasound is another tool to use for quality assurance in the clinical pathology laboratory. When combined 
with the rapid fixation protocol, tissue processing can be completed in less time with greater confidence that immunohistochemistry and other downstream bioassays will deliver accurate diagnosis to patients.

\section{Acknowledgments}

The authors would like to thank all the patients who consented to using their tissues for research, Daniel Chang and Sara Daniel at NW Biotrust (UWMC) for procuring tissue, and Torsten Leibold (VMSI) for support with the Ultrasound TOF instrument software modifications. The authors have disclosed that they have no significant relationships with, or financial interest in, any other commercial companies pertaining to this article.

\section{Author Disclosure Statement}

D.R.B., A.T., D.C., and M.O. are employees of Ventana Medical Systems, Inc. No competing financial interests exist for the remaining authors.

\section{Supplementary Material}

Supplementary Figure S1

Supplementary Table S1

\section{References}

1. Engel KB, Moore HM. Effects of preanalytical variables on the detection of proteins by immunohistochemistry in formalin-fixed, paraffin-embedded tissue. Arch Pathol Lab Med 2011;135:537-543.

2. Agrawal L, Engel KB, Greytak SR, Moore HM. Understanding preanalytical variables and their effects on clinical biomarkers of oncology and immunotherapy. Semin Cancer Biol 2018;52:26-38.

3. Werner M, Chott A, Fabiano A, et al. Effect of formalin tissue fixation and processing on immunohistochemistry. Am J Surg Pathol 2000;24:1016-1019.

4. Bass BP, Engel KB, Greytak SR, Moore HM. A Review of preanalytical factors affecting molecular, protein, and morphological analysis of formalin-fixed, paraffinembedded (FFPE) tissue: How well do you know your FFPE specimen? Arch Pathol Lab Med 2014;138:15201530.

5. Xie R, Chung J-Y, Ylaya K, et al. Factors influencing the degradation of archival formalin-fixed paraffin-embedded tissue sections. J Histochem Cytochem 2011;59:356-365.
6. Lerch ML, Bauer DR, Chafin D, Theiss A, Otter M, Baird GS. Precision medicine starts with preanalytics: Real-time assessment of tissue fixation quality by ultrasound time-offlight analysis. Appl Immunohistochem Mol Morphol 2017; 25:160-167.

7. Bauer DR, Stevens B, Taft J, et al. Dynamic subnanosecond time-of-flight detection for ultra-precise diffusion monitoring and optimization of biomarker preservation. In: Bosch JG, Doyley MM, eds. Proceedings of the SPIE Medical Imaging: Ultrasonic Imaging and Tomography. San Diego, CA: SPIE;Feb 15-20, 2014: 90400B.

8. Bauer DR, Stevens B, Chafin D, Theiss AP, Otter M. Active monitoring of formaldehyde diffusion into histological tissues with digital acoustic interferometry. J Med Imaging (Bellingham). 2016;3:017002.

9. Chafin D, Theiss A, Roberts E, Borlee G, Otter M, Baird GS. Rapid two-temperature formalin fixation. PLoS One 2013;8:e54138.

10. Giacomini A. Ultrasonic velocity in ethanol-water mixtures. J Acoust Soc Am 1947;19:701-702.

11. Tardajos G, Diaz Peña M, Aicart E. Speed of sound in pure liquids by a pulse-echo-overlap method. J Chem Thermodyn 1986;18:683-689.

12. Nebeker J, Nelson TR. Imaging of sound speed using reflection ultrasound tomography. J Ultrasound Med 2012;31:1389-1404.

13. Katz-Hanani I, Rothstein T, Gaitini D, Gallimidi Z, Azhari $\mathrm{H}$. Age-related ultrasonic properties of breast tissue in vivo. Ultrasound Med Biol 2014;40:2265-2271.

14. Zou N, Liang Q, He $\mathrm{H}$, et al. Ultrasound-facilitated formalin fixation of biological specimens. Biotech Histochem. 2011;86:413-420.

15. Grokhovsky SL, Il'icheva IA, Nechipurenko DY, et al. Sequence-specific ultrasonic cleavage of DNA. Biophys J 2011;100:117-125.

16. Dutour S, Lagourette B, Daridon JL. High-pressure speed of sound, density and compressibility of heavy normal paraffins: C $28 \mathrm{H} 58$ and $\mathrm{C} 36 \mathrm{H} 74$. J Chem Thermodyn 2002;34:475-484.

Address correspondence to:

Geoffrey S. Baird, MD, PhD Department of Laboratory Medicine University of Washington Medical Center 1959 NE Pacific Street, Box 357110

Seattle, WA 98195

E-mail: gbaird@uw.edu 